\title{
Klinikum Peterhof feierlich eröffnet
}

\author{
Neue Gesundheitseinrichtung der NÖGKK in Baden bietet stationäre und ambulante Rehabilitation.
}

Im Rahmen eines Festaktes eröffnete Bundesminister Rudolf Hundstorfer am 19. Oktober das neue Klinikum Peterhof in Baden. Das Klinikum Peterhof hat erst vor wenigen Wochen seinen Betrieb aufgenommen, dennoch ist es bereits ein Haus mit Tradition. Unter dem Namen Rheuma-Sonderkrankenanstalt Baden war

die Reha-Klinik der NÖGKK dreieinhalb Jahrzehnte lang Synonym für Spitzen-Rheumabehandlung in Niederösterreich. Der neue Peterhof ist aber mehr: Das Klinikum unter der neuen ärztlichen Leiterin Primaria Priv.-Doz. Dr. Valerie Nell-Duxneuner wurde massiv erweitert. Es hat heute 151 Betten, einen modernen und

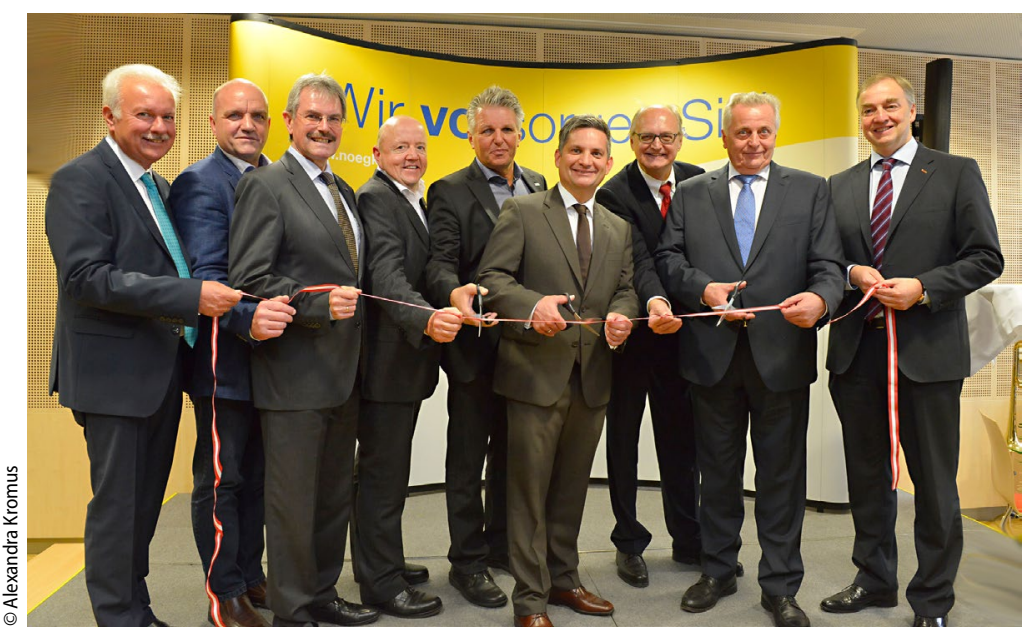

$\Delta$ v. I. n. r.: Bürgermeister Kurt Staska (Baden), AKNÖ-Präsident Markus Wieser, LR Mag. Karl Wilfing, Obmann Manfred Felix (Pensionsversicherungsanstalt), Obmann Gerhard Hutter

Quelle: Presseaussendung NÖGKK
(NÖGKK), LR Ing. Maurice Androsch, Generaldirektor Mag. Jan Pazourek (NÖGKK), Minister Rudolf Hundstorfer, WKNÖ-Vizepräsident Dr. Christian Moser hellen Spa-Bereich und kann von Schwefelbädern über Physio- und Ergotherapie bis zur psychologischen Beratung ein umfangreiches Therapieangebot offerieren. Bei der bewährten Behandlung des Bewegungs- und Stützapparates ist neben der stationären Behandlung außerdem auch ambulante Rehabilitation möglich. Neu ist zudem die Reha bei Lungenerkrankungen.

\section{Alles unter einem Dach}

Bei der Umgestaltung des Peterhof zum modernen Gesundheitszentrum beschritt die NÖGKK neue Wege und nutzte Synergien. „Im neuen Haus werden neben dem Klinikum auch die beiden Ambulatorien und das Service-Center der NÖGKK sowie das Ludwig-Boltzmann-Institut untergebracht", erklärte NÖGKK-Generaldirektor Mag. Jan Pazourek.,,Das spart uns in Zukunft Kosten."

rheuma plus $2015 \cdot 14: 92$

DOI 10.1007/s12688-015-0048-9

Online publiziert: 29. Oktober 2015

(c) Springer-Verlag Wien 2015

Absetzstudie

\section{Biologika-Deeskalation: Erste Erfahrungen aus den Niederlanden}

Auf Initiative der Kostenträger wurde in den Niederlanden eine Absetzstudie an erfolgreich mit Biologika behandelten Rheuma-Patienten durchgeführt. Sie sollte klären, ob der Stopp eine Alternative zum jährlichen Kostenanstieg um $\mathbf{3 0 - 4 0 \% ~ i s t . ~}$

Das immerhin 817 Patienten mit im Mittel seit elf Jahren bestehender, seropositiver, erosiver rheumatoider Arthritis (RA) umfassen- de multizentrische, randomisierte, kontrollierte Experiment stellte Prof. Piet van Riel, Universität Nijmegen, Niederlande, beim diesjährigen Kon- gress der Deutschen Gesellschaft für Rheumatologie vor. Es trägt den prosaischen Namen POET-TNFiSTOP. Verglichen wurde das Absetzen (2/3) mit 